\title{
Research of the cutting of materials used in heavy power engineering by means of the carbide cutting tools with nanoscale wear-resistant coating
}

\author{
Marina A. Volosova, Yury A. Melnik, Alexey A. VereschakA a and Dmitry N. Lytkin \\ Moscow State University of Technology "STANKIN", 1 Vadkovsky per., Moscow GSP-4, 127994, Russian Federation
}

Received 3 October 2016, Accepted 6 December 2016

\begin{abstract}
The paper presents the results of the studies focused on the specifics of cutting of materials, used in manufacturing of heavy power engineering products, on the example of longitudinal turning of steel 9SiMn16. To improve such important parameters of cutting as tool life and reliability of carbide tools, it is proposed to use nanoscale multilayer composite coatings, in particular, Ti-TiN-(TiCrAl)N and Zr-ZrN$(\mathrm{ZrNbCrAl}) \mathrm{N}$, produced using the filtered cathodic vacuum arc deposition (FCVAD). It was found out that the use of carbide tools with developed coatings results not only in reduction of cutting forces by 20$25 \%$, but also in substantial reduction of force variation as compared with the corresponding parameters for uncoated tools, which allows improvement of cutting quality. The proposed nanoscale multilayer composite coatings provide significant increase in tools useful life as compared with the standard TiN coating.
\end{abstract}

Key words: Nanoscale multilayer composite coatings / filtered cathodic vacuum arc deposition / cutting forces

\section{Introduction}

Machining of heavy power engineering products (in particular, reactor vessels) has a number of significant features. In particular, pre-machining of workpieces for above products, for example, through forging, results in a significant change in their surface properties and, in particular, increases surface hardness and forms areas with abrasive inclusions and high irregularity of allowance. Meanwhile, there are still quite high quality requirements for workpiece surfaces that are comparable with similar requirements, such as applied in automotive and aircraft industries [1]. The above becomes the reason for sharp deterioration in workability of workpieces used in heavy power engineering. A typical part of large heavy engineering products is a reactor vessel. To increase its security it is necessary to increase the sidewall active zone, wherein welds are made outside the core, and that fact increases the complexity of its machining. Heavy power engineering also uses other large-size products (such as rotors, manifolds, tube sheets, etc.), whose workpieces are subjected to post-machining after preliminary forging. For this reason, the main objective of this research was to develop a carbide tools with useful life increased due to the use

${ }^{a}$ Corresponding author: ecotech@rambler.ru of a nanoscale multilayer composite coatings on carbide substrates.

\section{Cutting process evaluation}

For the qualitative and quantitative evaluation of the cutting process, the research was focused on the study of cutting forces and force variation, as well as wear mechanisms and behavior and wear-resistance data for tools with the developed coatings in comparison with those for uncoated tools and tools with "reference" commercial coating.

For the cutting process, it is necessary to apply to a tool the force, which overcomes the resistance of the material being machined against penetration of a foreign body and separation of some material (chipping). Change in the cutting force indicates the change in energy generated during the cutting and results in change of temperature occurring at the cutting.

The cutting force arising in longitudinal turning of material is usually spread on three axes in a rectangular coordinate system that correspond to the directions of motion of cutting speed vector $F_{\mathrm{C}}$, feed force $F_{\mathrm{f}}$ and vector of tool release from workpiece $F_{\mathrm{P}}$. These three vectors form a hodograph of forces with resultat force $F_{Z}$ and a 


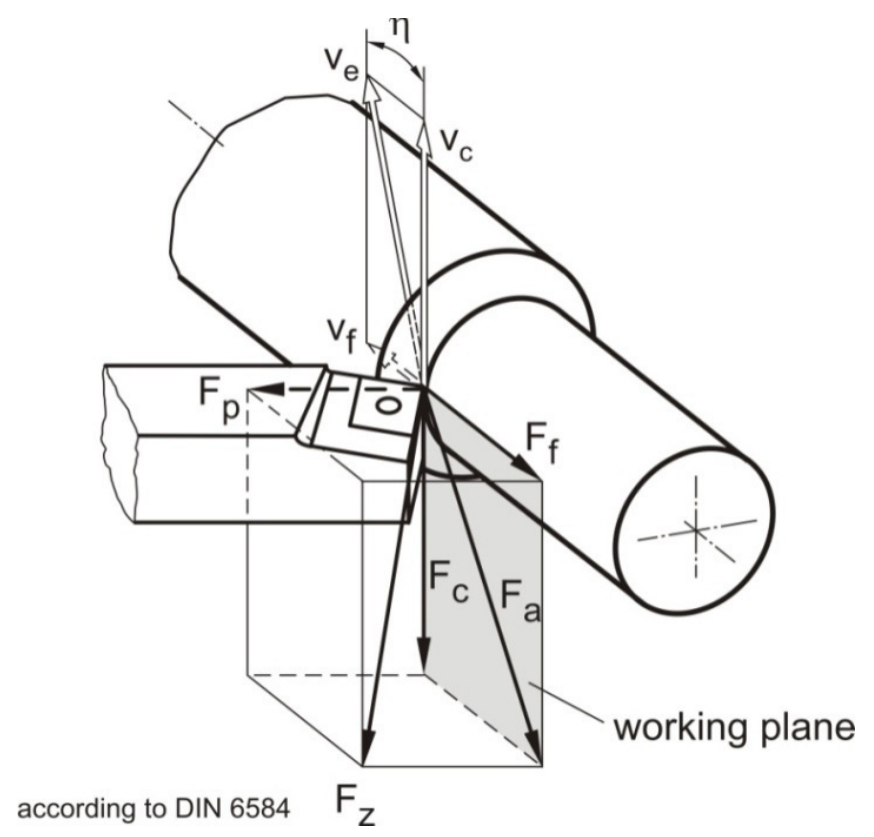

Fig. 1. Measured cutting-force components.

plane with active component of cutting force $F_{\mathrm{a}}(1)$ [2-6].

$$
\overrightarrow{F_{Z}}=\overrightarrow{F_{C}}+\overrightarrow{F_{a}}+\overrightarrow{F_{P}} .
$$

Since the tool makes no shaping movement in the direction of passive force component $F_{\mathrm{P}}$, then it plays no role in the conversion of energy. However, the radial force $F_{\mathrm{P}}$ significantly affects release of a tool from a workpiece and the machining accuracy. The active component of the cutting force $P_{\mathrm{a}}$ in the coordinate system is decomposed into two components $F_{\mathrm{C}}$ and $F_{\mathrm{f}}$ (Fig. 1) [2-6].

Power required for the cutting results from multiplication of cutting speed and one of the components of the cutting force $\left(F_{\mathrm{C}}\right)$, acting in that direction (Fig. 1) [2-6].

Cutting power is calculated as follows:

$$
N_{C}=F_{C} t V_{C}
$$

where $V_{\mathrm{C}}$ - cutting speed.

Accordingly, the power required for machining process or cutting power is in direct relationship with the tangential component of the cutting force (3).

$$
A_{C}=F_{C} V_{C} T_{C},
$$

where $T_{\mathrm{C}}$ - cutting time.

According to the comparative wear-resistance tests carried out earlier [7], at cutting of steel 9SiMn16 with close properties, the longest tool life was shown by carbide tools with nanoscale multilayer composite coatings (NMCC) Ti-TiN-(TiCrAl)N and Zr-ZrN-(ZrNbCrAl)N, deposited through filtered cathodic vacuum arc deposition (FCVAD) [8-11] (see Fig. 2). Meanwhile, the tool with NMCC Zr-ZrN-(ZrNbCrAl)N showed the longest tool life.

Based on the above, for the further research, the tools with NMCCZr-ZrN-(ZrNbCrAl)N were selected for the study of cutting forces and with NMCC Ti-TiN(TiCrAl)N and Zr-ZrN-(ZrNbCrAl)N for comparative wear-resistance tests and study of tool wear behaviour.

\section{Experimental procedure}

The tests were conducted on a CNC lathe Index GU 600. The tests included cutting inserts SNGN 120412, fixed in holders with the main angle in terms of $75^{\circ}$. Steel 9SiMn16 (find chemical composition in Tab. 1) was used as the material being machined, and carbides of various brands were used as tool materials.

Cutting was carried out at the following cutting conditions: $V_{\mathrm{C}}=120 \mathrm{~m} \cdot \mathrm{min}^{-1}, f=0.1 \mathrm{~mm} \cdot \mathrm{rev}^{-1}, a_{\mathrm{p}}=3 \mathrm{~mm}$.

The cutting forces were measured with a threecomponent force dynamometer (Kistler Type 9121) mounted on the turret disk of the CNC lathe Index GU 600 via turret adapter for the tool holder creating a very rigid tooling fixture. The charge signal generated at the dynamometer was amplified using charge amplifiers (Kistler Type 5814B1). The amplified signal is acquired and sampled by using a data acquisition PCMCIA card and Kistler Dyno Ware software on a computer at a sampling frequency of $2000 \mathrm{~Hz}$ per channel. Time-series profiles of the acquired force data reveal that the forces are relatively constant over the length of cut and factors such as vibration and spindle run-out were negligible.

For microstructural studies of samples of carbide with coatings, a raster electron microscope FEI Quanta 600 FEG was used. The studies of chemical composition were conducted with the use of the same raster electron microscope. To perform X-ray microanalysis, the study used characteristic X-ray emissions resulting from electron bombardment of a sample.

\section{Results and discussion}

Was performed For cutting inserts of carbide without coating and with NMCC Zr-ZrN-(ZrNbCrAl)N (FCVAD) experimental study of cutting force $\left(F_{\mathrm{c}}\right)$, feed force $\left(F_{\mathrm{f}}\right)$, passive force $\left(F_{\mathrm{p}}\right)$ has been carried out. The study found out:

- decrease of all three components of the cutting force $\left(F_{\mathrm{c}}, F_{\mathrm{f}}, F_{\mathrm{p}}\right)$ for tools with NMCC Zr-ZrN$(\mathrm{ZrNbCrAl}) \mathrm{N}(\mathrm{FCVAD})$ as compared with uncoated tools;

- considerable decrease in force variation for all three components of the cutting force $\left(F_{\mathrm{c}}, F_{\mathrm{f}}, F_{\mathrm{p}}\right)$ for a tool with NMCC Zr-ZrN-(ZrNbCrAl)N (FCVAD) as compared with uncoated tools, when the maximum value of force variation was observed for cutting force $\left(F_{\mathrm{c}}\right)$, and the minimum value - for passive force $\left(F_{\mathrm{p}}\right)$.

The obtained data were processed in accordance with the following algorithm in order to obtain typical average values of cutting forces and force variation. The results are presented in Table 2 . 

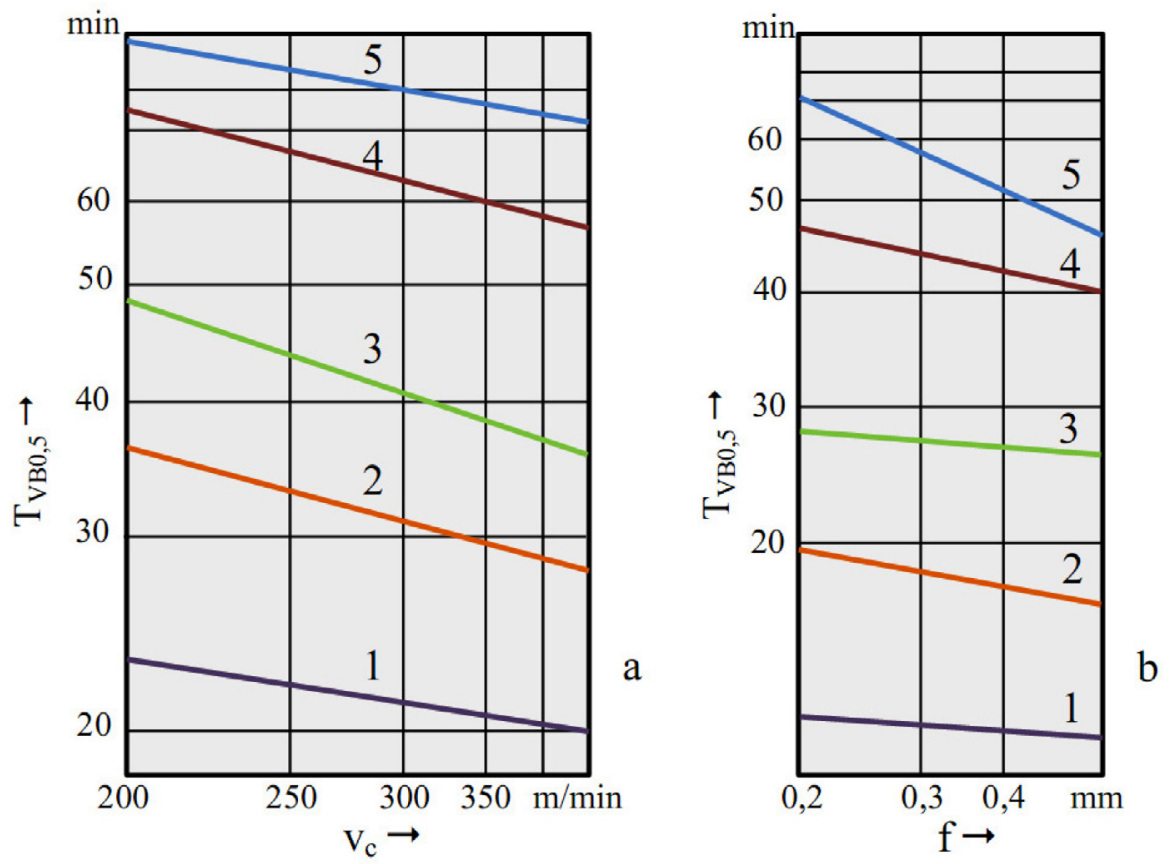

Fig. 2. Influence of cutting speed $v_{\mathrm{c}}$ (a) and feed $f(\mathrm{~b})$ on lifetime of the carbide inserts with various NMCC at longitudinal turning steels 9SiMn16 at $a_{\mathrm{p}}=1.5 \mathrm{~mm}: 1$ - reference uncoated tool; 2 - TiN (Standard arc-PVD technology); 3 - CrCrAlN-(NbZrCrAl)N (FCVAD); $4-$ Ti-TiN-(TiCrAl)N (FCVAD); $5-$ Zr-ZrN-(ZrNbCrAl)N (FCVAD); $a_{\mathrm{p}}=3.0 \mathrm{~mm} ; f=$ $0.8 \mathrm{~mm} \cdot \mathrm{rev}^{-1} ; v_{\mathrm{c}}=300 \mathrm{~m} \cdot \mathrm{min}^{-1}$.

Table 1. Chemical composition of steel 9SiMn16.

\begin{tabular}{cccccccccc}
\hline $\mathrm{C}$ & $\mathrm{Si}$ & $\mathrm{Mn}$ & $\mathrm{Ni}$ & $\mathrm{S}$ & $\mathrm{P}$ & $\mathrm{Cr}$ & $\mathrm{N}$ & $\mathrm{Cu}$ & $\mathrm{As}$ \\
\hline up to 0.12 & $0.5-0.8$ & $1.3-1.7$ & up to 0.3 & up to 0.04 & up to 0.035 & up to 0.3 & up to 0.008 & up to 0.3 & up to 0.08 \\
\hline
\end{tabular}

Here $F_{\mathrm{c}}$ is cutting force; $F_{\mathrm{f}}$ is feed force; $F_{\mathrm{p}}$ is passive force ; $Y$ is the data dispersion determined as follows:

$$
\begin{aligned}
Y & =\frac{1}{n-1} \sum_{i=1}^{n}\left(F_{i}-\langle F\rangle\right)^{2} \\
\langle F\rangle & =\frac{1}{n} \sum_{i=0}^{n} F_{i}
\end{aligned}
$$

where $F$ is cutting force, $n$ is the number of processed data points, RMSD is the root mean square deviation determined through the following formula:

$$
\mathrm{RMSD}=\sqrt{\frac{1}{n-1} \sum_{i=1}^{n}\left(F_{i}-\langle F\rangle\right)^{2}}
$$

ARV is average rectified value, which is arithmetic average of absolute instantaneous values over the period of time for data processing. It is determined through the following formula:

$$
\begin{aligned}
F_{A R V} & =\frac{1}{n} \sum_{i=1}^{n}\left|F_{i}\right| \\
Y & =\sqrt{\frac{1}{T} \int_{0}^{T} F^{2} \partial t}
\end{aligned}
$$

where $K_{\mathrm{f}} \mathrm{s}$ the form factor equal to the ratio of the RMSD value to the ARV value; $K c$ is the crest factor equal to the ratio of the amplitude to the RMSD value.

The obtained data allowed comparison of cutting forces and force variation for carbide tools without coating and with NMCC Zr-ZrN-(ZrNbCrAl)N (FCVAD). The calculation results are presented in the form of diagrams in Figures 3 and 4.

Deposition of NMCC Zr-ZrN-(ZrNbCrAl)N (FCVAD) on a carbide tool reduces cutting forces (up to 25\%) and stabilizes the cutting process due to significant reduction in force variation between the maximum and minimum values of the cutting force. The latter allows predicting the likelihood of a significant increase in tool life of carbide tools with developed NMCC due to reduction of vibrations generated at cutting.

Flank wear land $V B_{c}=0.45-0.5 \mathrm{~mm}$ was taken as a failure criteria. It was measured with toolmaker's microscope MBS-10 as the arithmetic mean of four to five tests. The results were processed using parametric identification of exponential stochastic multiplicative mathematical model by least squares method. Curves obtained by mathematical processing of the experimental data are shown in Figure 5 and 6.

The tool with NMCC Zr-ZrN-(ZrNbCrAl)N (FCVAD) showed a significantly longer tool life under all the tested 
M.A. Volosova et al.: Mechanics \& Industry 17, 711 (2016)

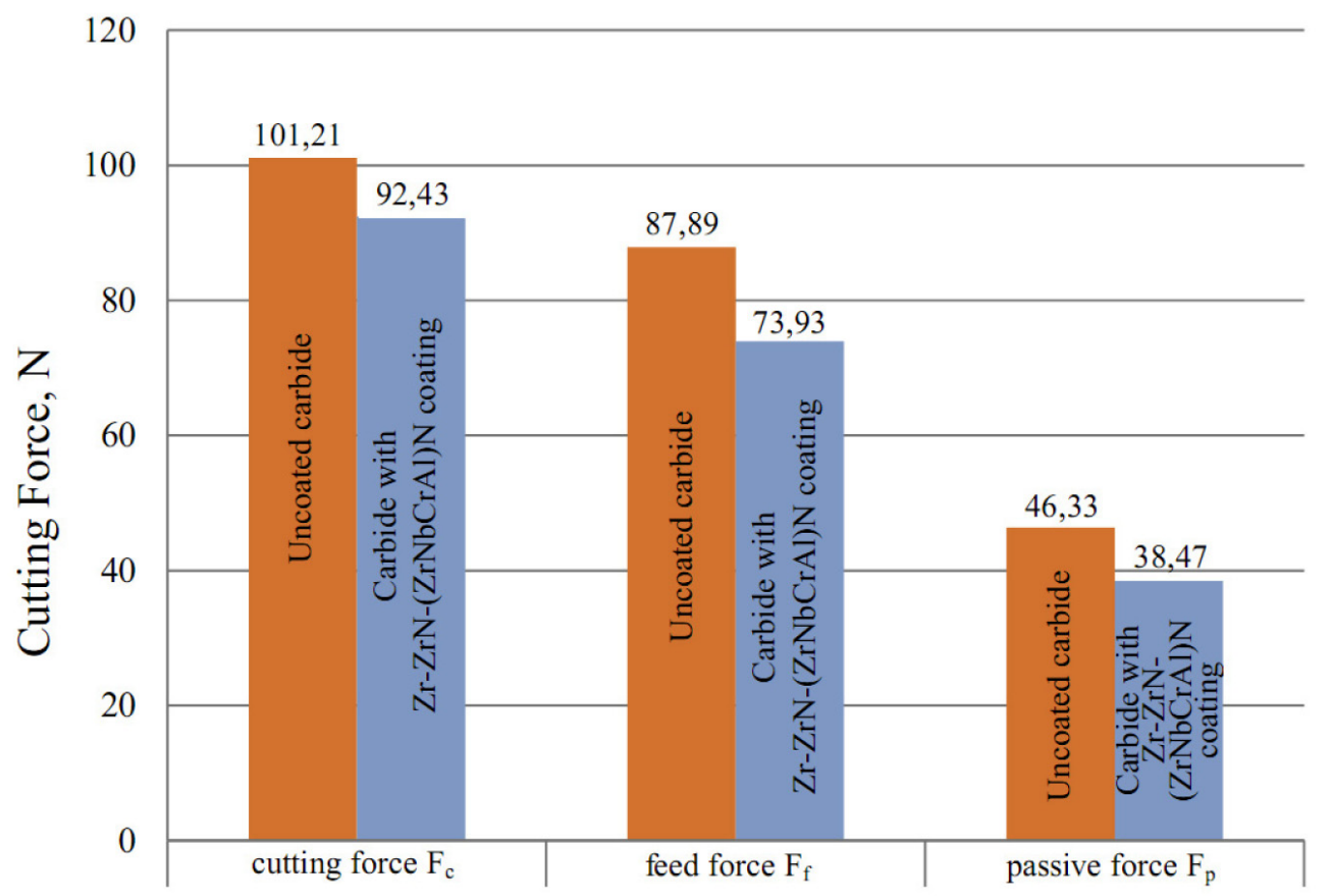

Fig. 3. Average value of cutting force $F_{\mathrm{c}}$, feed force $F_{\mathrm{f}}$ and passive force $F_{\mathrm{p}}$ for carbide tools without coating and with NMCC Zr-ZrN-(ZrNbCrAl)N (FCVAD).

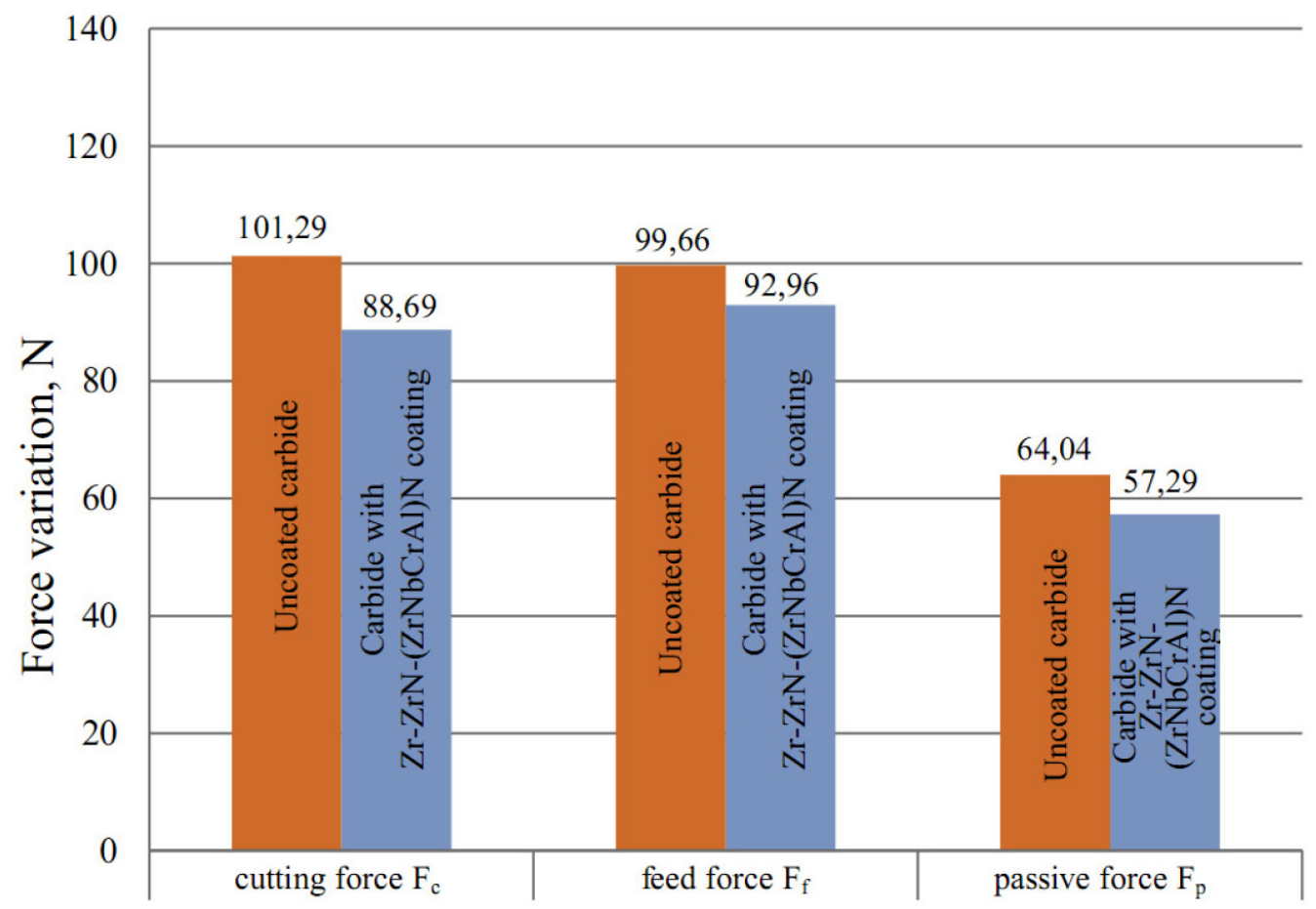

Fig. 4. Value of variation of cutting force $F_{\mathrm{c}}$, feed force $F_{\mathrm{f}}$ and passive force $F_{\mathrm{p}}$ for carbide tools without coating and with NMCC Zr-ZrN-(ZrNbCrAl)N (FCVAD). 
M.A. Volosova et al.: Mechanics \& Industry 17, 711 (2016)

Table 2. Results of processing of experimental data obtained in steel 9 SiMn16 tuning at $V_{\mathrm{C}}=120 \mathrm{~m} \cdot \mathrm{min}^{-1}, F=0.1 \mathrm{~mm} \cdot \mathrm{rev}^{-1}$, $a_{\mathrm{p}}=3 \mathrm{~mm}$.

\begin{tabular}{|c|c|c|c|}
\hline \multicolumn{4}{|l|}{ Uncoated carbide } \\
\hline Channel & $F_{\mathrm{c}}, \mathrm{N}$ & $F_{\mathrm{f}}, \mathrm{N}$ & $F_{\mathrm{p}}, \mathrm{N}$ \\
\hline $\mathrm{T}(\mathrm{s})$ & 153.61 & 153.61 & 153.61 \\
\hline Sampling frequency of signal & 150.15 & 150.15 & 150.15 \\
\hline Number of data processing points & 23065 & 23065 & 23065 \\
\hline The minimum value of the signal & 67.69 & 68.8 & 31.97 \\
\hline The maximum value of the signal & 168.98 & 168.46 & 96.01 \\
\hline The average value of the processed signal & 101.21 & 87.89 & 46.33 \\
\hline Dispersion of data $(\mathrm{Y})$ & 245.78 & 279.09 & 56.09 \\
\hline RMSD (root mean square deviation) & 15.68 & 16.71 & 7.49 \\
\hline Amplitude & 168.98 & 168.46 & 96.01 \\
\hline $\begin{array}{l}\text { Variation (the difference between the maximum } \\
\text { and minimum values of cutting force) }\end{array}$ & 101.29 & 99.66 & 64.04 \\
\hline Average rectified value (ARV) & 101.21 & 87.89 & 46.33 \\
\hline Actual value of the initial data & 102.42 & 89.46 & 46.93 \\
\hline The form factor $\left(K_{\mathrm{f}}\right)$ & 1.01 & 1.02 & 1.01 \\
\hline Crest factor $\left(K_{\mathrm{c}}\right)$ & 1.65 & 1.88 & 2.05 \\
\hline \multicolumn{4}{|c|}{ Carbide with NMCCZr - ZrN - (ZrNbCrAl)N (FCVAD) } \\
\hline Channel & $F_{\mathrm{c}}, \mathrm{N}$ & $F_{\mathrm{f}}, \mathrm{N}$ & $F_{\mathrm{p}}, \mathrm{N}$ \\
\hline $\mathrm{T}(\mathrm{s})$ & 140.9 & 140.9 & 140.9 \\
\hline Sampling frequency of signal & 150.15 & 150.15 & 150.15 \\
\hline Number of data processing points & 21157 & 21157 & 21157 \\
\hline The minimum value of the signal & 63.64 & 61.98 & 28.6 \\
\hline The maximum value of the signal & 152.34 & 154.94 & 85.88 \\
\hline The average value of the processed signal & 92.43 & 73.93 & 38.47 \\
\hline Dispersion of data $(\mathrm{Y})$ & 137.04 & 183.27 & 37.91 \\
\hline RMSD (root mean square deviation) & 11.71 & 13.54 & 6.16 \\
\hline Amplitude & 152.34 & 154.94 & 85.88 \\
\hline $\begin{array}{l}\text { Variation (the difference between the maximum } \\
\text { and minimum values of cutting force) }\end{array}$ & 88.69 & 92.96 & 57.29 \\
\hline Average rectified value (ARV) & 92.43 & 73.93 & 38.47 \\
\hline Actual value of the initial data & 93.17 & 75.16 & 38.96 \\
\hline The form factor $\left(K_{\mathrm{f}}\right)$ & 1.01 & 1.02 & 1.01 \\
\hline Crest factor $\left(K_{\mathrm{c}}\right)$ & 1.64 & 2.06 & 2.2 \\
\hline
\end{tabular}

machining conditions (tool life increased by up to 2-2.5 times and higher) as compared with tool life of the tool with "reference" TiN coating.

The wear behavior of the tool with developed NMCC shows fairly stable and balanced wear of contact areas of rake and flank faces of cutting tool without visible chips and centers of brittle fracture in transition to a phase of catastrophic wear, so typical for uncoated carbide tools and tools with "reference" TiN coating.

The tool with NMCC Ti-TiN-(TiCrAl)N (FCVAD) showed a marked increase in tool life at cutting with low and average values of cutting conditions $\left(a_{\mathrm{p}}=0.5-1.2 \mathrm{~mm} ; f=0.1-0.15 \mathrm{~mm} \cdot \mathrm{rev}^{-1} ; v_{\mathrm{C}}=\right.$ 250-300 m.min $\left.{ }^{-1}\right)$. When cutting conditions are enhanced due to increase in depth of cut $a_{\mathrm{p}}$ and feed $f$, tool life of the tool with developed NMCC is close to tool life of the tool with "reference" TiN coating.

However, in this case, the wear behavior of the tool with NMCC Ti-TiN-(TiCrAl)N (FCVAD) shows a decrease in the intensity of the phase of catastrophic wear in the absence of brittle chipping of large volumes of carbide. The latter is apparently connected with the active formation of oxide films of high hardness of $\mathrm{Al}_{2} \mathrm{O}_{3}$ type, formed in the cutting zone [12].

The tool with NMCC Zr-ZrN-(ZrNbCrAl)N showed the longest tool life under all the cutting conditions under study according to the achieved wear behavior of the tested coatings under various cutting conditions. When the cutting speed is increased up to $v_{\mathrm{c}}=350 \mathrm{~m} \cdot \mathrm{min}^{-1}$, the tool life decreases for all the coated tools. However, for the tool with "reference" TiN coating, the above decrease in tool life is less pronounced (by 1.6 times) as compared with the decrease in tool life of the tool with developed NMCC Zr-ZrN-(ZrNbCrAl)N (decrease in tool life by 2.8 times for the tool with NMCC and by 3.8 times for the tool with NMCC Ti-TiN-(TiCrAl)N). This may be connected with higher wear resistance of carbide at elevated temperatures of cutting due to increase in resistance to high-temperature softening of carbide at deposition of developed NMCC. Increase in feed $f$ from 0.1 up to $0.2 \mathrm{~mm} \cdot \mathrm{rev}^{-1}$ has a little effect on tool life of a tool with "reference" TiN coating, while the above effect is higher for a tool with NMCC Zr-ZrN-(ZrNbCrAl)N (tool life decreases by 20\%). For a tool with NMCC Ti-TiN- 
M.A. Volosova et al.: Mechanics \& Industry 17, 711 (2016)

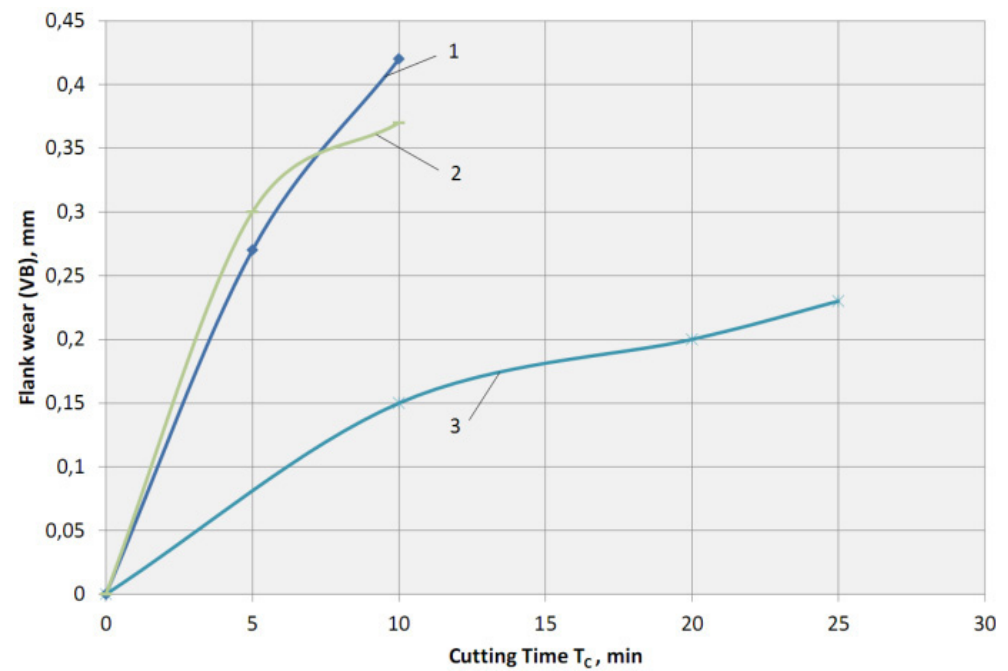

(a)

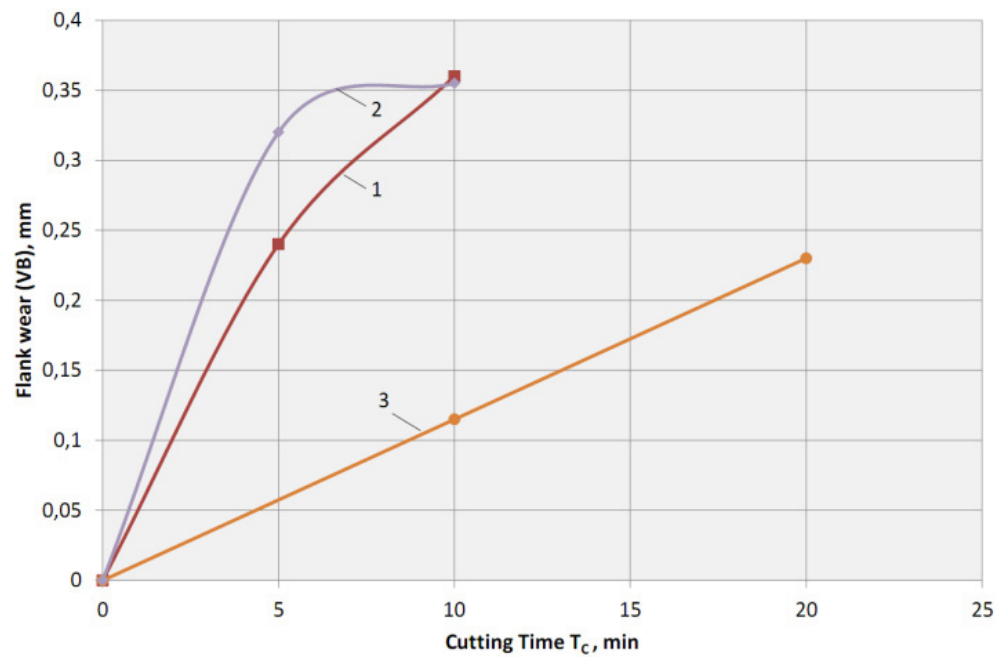

(b)

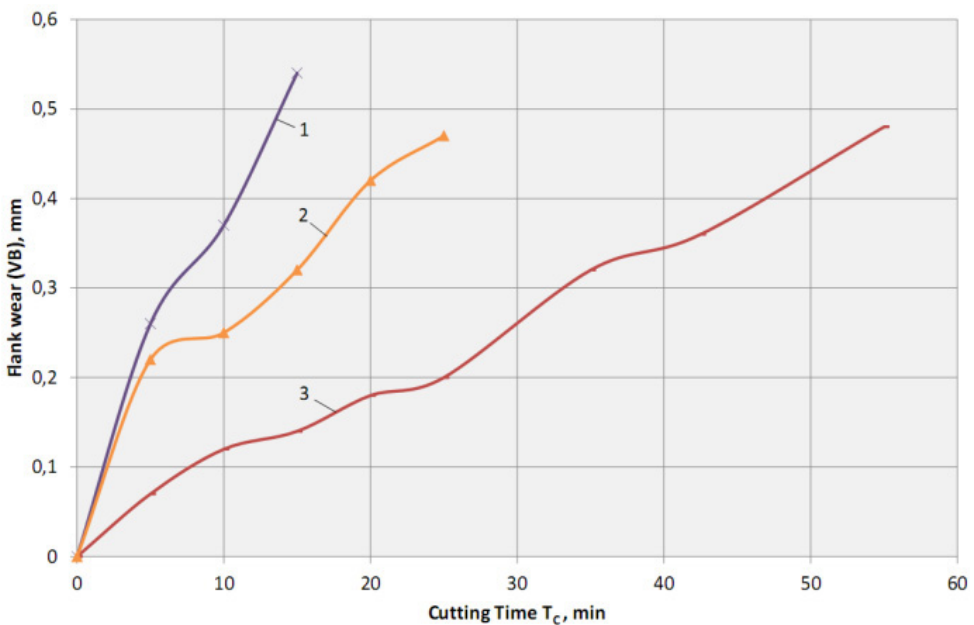

(c)

Fig. 5. Dependence of wear VB on cutting time at dry turning of steel 9 SiMn16, where (a) $a_{\mathrm{p}}=1.0 \mathrm{~mm} ; f=0.1 \mathrm{~mm}^{\mathrm{r}} \mathrm{rev}^{-1}$; $v_{\mathrm{C}}=250 \mathrm{~m} \cdot \mathrm{min}^{-1} ;$ (b) $a_{\mathrm{p}}=0 ., 5 \mathrm{~mm} ; f=0.2 \mathrm{~mm} \cdot \mathrm{rev}^{-1} ; v_{\mathrm{C}}=250 \mathrm{~m} \cdot \mathrm{min}^{-1} ;$ (c) $a_{\mathrm{p}}=0.5 \mathrm{~mm} ; f=0.1 \mathrm{~mm} \cdot \mathrm{rev}{ }^{-1}$; $v_{\mathrm{C}}=250 \mathrm{~m} \cdot \mathrm{min}^{-1} ; 1$ - "reference" TiN coating; 2 - NMCCTi-TiN-(TiCrAl)N (FCVAD); 3 -NMCC Zr-ZrN-(ZrNbCrAl)N (FCVAD). 
M.A. Volosova et al.: Mechanics \& Industry 17, 711 (2016)

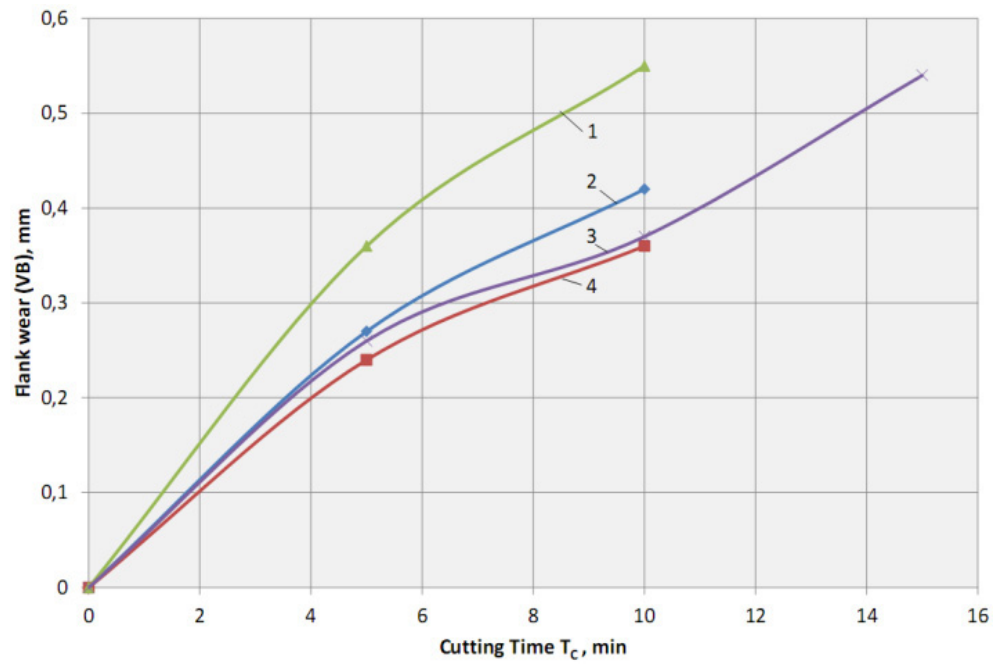

(a)

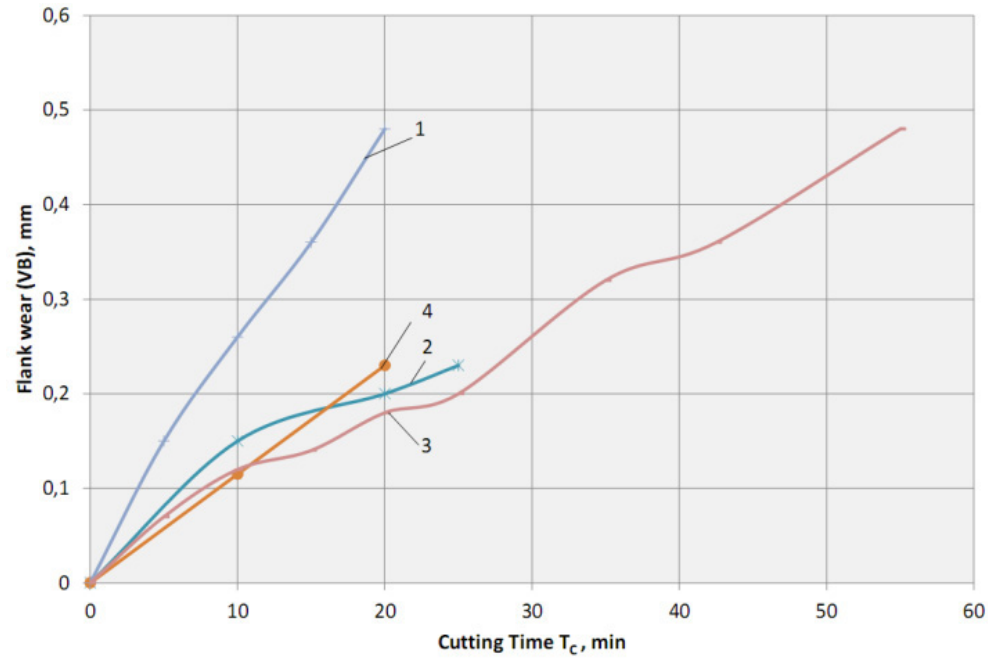

(b)

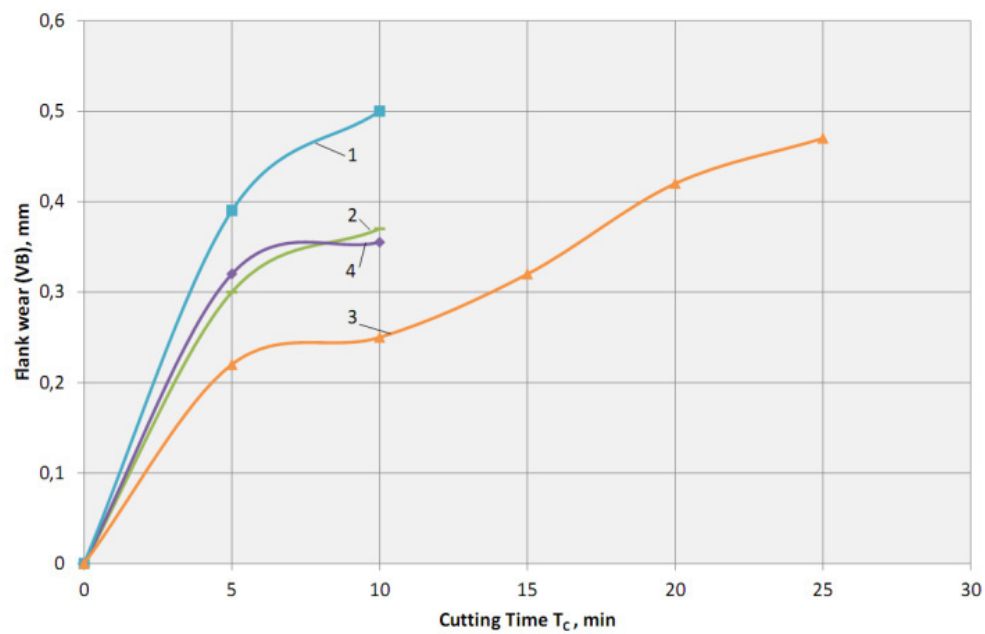

(c)

Fig. 6. Dependence of wear VB on cutting time at dry turning of steel 9SiMn16, where (a) carbide with "reference" TiN coating; (b) carbide with NMCC Zr-ZrN-(ZrNbCrAl)N; (c) carbide with NMCC Ti-TiN-(TiCrAl)N at: $1-a_{\mathrm{p}}=0.5 \mathrm{~mm}$; $f=0.1 \mathrm{~mm} \cdot \mathrm{rev}^{-1} ; v_{\mathrm{C}}=350 \mathrm{~m} \cdot \mathrm{min}^{-1} ; 2-a_{\mathrm{p}}=1.0 \mathrm{~mm} ; f=0.1 \mathrm{~mm} \cdot \mathrm{rev}^{-1} ; v_{\mathrm{C}}=250 \mathrm{~m} \cdot \mathrm{min}^{-1} ; 3-a_{\mathrm{p}}=0.5 \mathrm{~mm}$; $f=0.1 \mathrm{~mm} \cdot \mathrm{rev}^{-1} ; v_{\mathrm{C}}=250 \mathrm{~m} \cdot \mathrm{min}^{-1} ; 4-a_{\mathrm{p}}=0.5 \mathrm{~mm} ; f=0.2 \mathrm{~mm} \cdot \mathrm{rev}^{-1} ; v_{\mathrm{C}}=250 \mathrm{~m} \cdot \mathrm{min}^{-1}$. 
(TiCrAl)N, the effect reaches its maximum (tool life decreases by almost 2 times). This effect may also be connected with the lower influence of feed on temperature in the cutting zone as compared with the influence of the cutting speed and feed on strength characteristics of carbide. Increase in depth of cut $a_{\mathrm{p}}$ from 0.5 up to $1 \mathrm{~mm}$ results in a slight decrease in tool life of a tool with "reference" TiN coating and with NMCC Zr-ZrN-(ZrNbCrAl)N (decrease by 20-25\%), while for a tool with NMCC TiTiN-(TiCrAl)N, the decrease is more significant (decrease by 1.7 times).

The metallographic tests of coating structures were conducted to understand the considerably strong effect of cutting parameters on intensity of wear and wear behavior of carbide tools at deposition of the coatings under study. Figures 7-9 present SEM-images, obtained on cross-sections of the following compositions: "carbide substrate-TiN", "carbide substrate-Ti-TiN-(TiCrAl)N", and "carbide substrate-Zr-ZrN-(ZrNbCrAl)N".

The results of metallographic tests of carbide tools with coating TiN are presented in Figure 7.

According to the results of metallographic tests of composition "carbide substrate-TiN", obtained through the arc-PVD technology presented in Figure 8 the thickness of coating TiN is $3.32-3.43 \mu \mathrm{m}$. Coating TiN with single-layer architecture has a definite "columnar" structure, typical for coatings TiN, formed at carbide substrates using the arc-PVD technology. Wear of carbide tool with coating TiN is of definite abrasive and adhesionfatigue pattern. Formation of builds-up edge is observed along flank face and in a wear crater (Fig. 7b). The tests reveal active crack formation predominantly in the form of longitudinal cracks in the structure of coating on rake face of the tool (Fig. 7c).

Figure 8 present SEM-images obtained in crosssection of composition "carbide-Ti-TiN-(TiCrAl)N" with NMCC, formed through the FCVAD technology.

The results of the tests of the structure of NMCC TiTiN-(TiCrAl)N, deposited on carbide substrate through the FCVAD technology allows to obtain the thickness of NMCC Ti-TiN-(TiCrAl)N 2.7-2.8 $\mu \mathrm{m}$. NMCC TiTiN-(TiCrAl)N has a three-layer architecture with adhesive $\mathrm{Ti}$ layer (with thickness of $0.5-0.6 \mu \mathrm{m}$ ), intermediate layer TiN (with thickness of 0.9-1.0 $\mu \mathrm{m}$ ), and wear-resistant layer ( $\mathrm{TiCrAl}) \mathrm{N}$ (with thickness of 1.0$1.1 \mu \mathrm{m})$. NMCC Ti-TiN-(TiCrAl)N consists of sublayers of nanoscale thickness in structure of intermediate and wear-resistant layers with thickness of $60-120 \mathrm{~nm}$. Structure of adhesive sublayer NMCC Ti-TiN-(TiCrAl)N includes microdroplets of up to $0.6 \mu \mathrm{m}$, which distort structure of subsequent layers. Wear of carbide tool with NMCC Ti-TiN-(TiCrAl)N is defined by abrasive wear mechanism (to a lesser extent) and adhesion-fatigue wear mechanism (prevailing wear mechanism). The tests revealed formation of builds-up edge along flank face and in a wear crater (Fig. 8b). The tests also pointed to active crack formation in the structure of coating along rake face, in particular, active formation of longitudinal cracks and delamination (Fig. 8c).
Results of the structure tests and wear mechanisms for a carbide tool with NMCC $\mathrm{Zr}-\mathrm{ZrN}-(\mathrm{ZrNbCrAl}) \mathrm{N}$ are presented in Figure 9.

The tests of the structure of NMCC Zr-ZrN$(\mathrm{ZrNbCrAl}) \mathrm{N}$, deposited on a carbide tool through the FCVAD technology allow to obtain the total thickness of NMCC 3.7-3.8 $\mu \mathrm{m}$ (Fig. 9c). Coating has a three-layer architecture with adhesive layer $\mathrm{Ti}$ (with thickness of $0.5-$ $0.6 \mu \mathrm{m}$ ), intermediate layer of TiN (with thickness of 1.5$1.6 \mu \mathrm{m}$ ), and wear-resistant layer ( $\mathrm{TiCrAl}$ ) N (with thickness of $1.5-1.6 \mu \mathrm{m})$. Structure of intermediate and wearresistant layers of NMCC $\mathrm{Zr}-\mathrm{ZrN}-(\mathrm{ZrNbCrAl}) \mathrm{N}$ includes sublayers of nanoscale thickness of $40-100 \mathrm{~nm}$, and on the surface of NMCC are revealed numerous microdroplets.

The analysis of wear behavior for NMCC Zr-ZrN$(\mathrm{ZrNbCrAl}) \mathrm{N}$ reveals the following results. Wear of a carbide tool is defined by mechanisms of abrasive and adhesion-fatigue wear, the latter prevailing. Formation of builds-up edge of the material being machined along the flank tool face, as well as considerably deep penetration of the material being machined into the carbide structure (Fig. 9b). Active crack formation in the structure of coating on rake face, with prevailing formation of transverse cracks (Fig. 9c). Active chipping of coating components in the area directly adjacent to the tool cutting edge with subsequent formation of builds-up edge consisting of particles of the material being machined (Fig. 9b). Dynamic failure of coating originating around a microdroplet, as well as presence of a number of numerous through cracks (Fig. 9c).

\section{Conclusions}

The study results show a decrease in cutting force $F_{\mathrm{c}}$, feed force $F_{\mathrm{f}}$ and passive force $F_{\mathrm{p}}$ by $20-25 \%$ with considerable decrease in force variation. Wear behavior of the tested coatings under various cutting conditions reveals that the tool with NMCC $\mathrm{Zr}-\mathrm{ZrN}-(\mathrm{ZrNbCrAl}) \mathrm{N}$ coatings have the longest useful life. Wear of carbide tool with NMCC Ti-TiN-(TiCrAl)N is defined by abrasive wear mechanism and adhesion-fatigue wear mechanism (prevailing wear mechanism).

The analysis of the wear behavior of carbide tools with coatings under study shows that adhesion-fatigue wear mechanism is prevailing for carbide tools with all the tested coatings. The mechanism of adhesion-fatigue wear is defined with formation of longitudinal cracks in coating and is typical for tools with coatings of "reference" TiN coating and NMCC $\mathrm{Zr}-\mathrm{ZrN}-(\mathrm{ZrNbCrAl}) \mathrm{N}$. For tools with NMCC Ti-TiN-(TiCrAl)N coating, adhesion-fatigue wear is defined by formation of transverse cracks. All three types of coatings are prone to formation of buildsup of the material being machined in the area adjacent to cutting edge.

Acknowledgements. This work was carried out with the financial support of the Ministry of Education and Science of Russian Federation in the framework of the state task in the field 


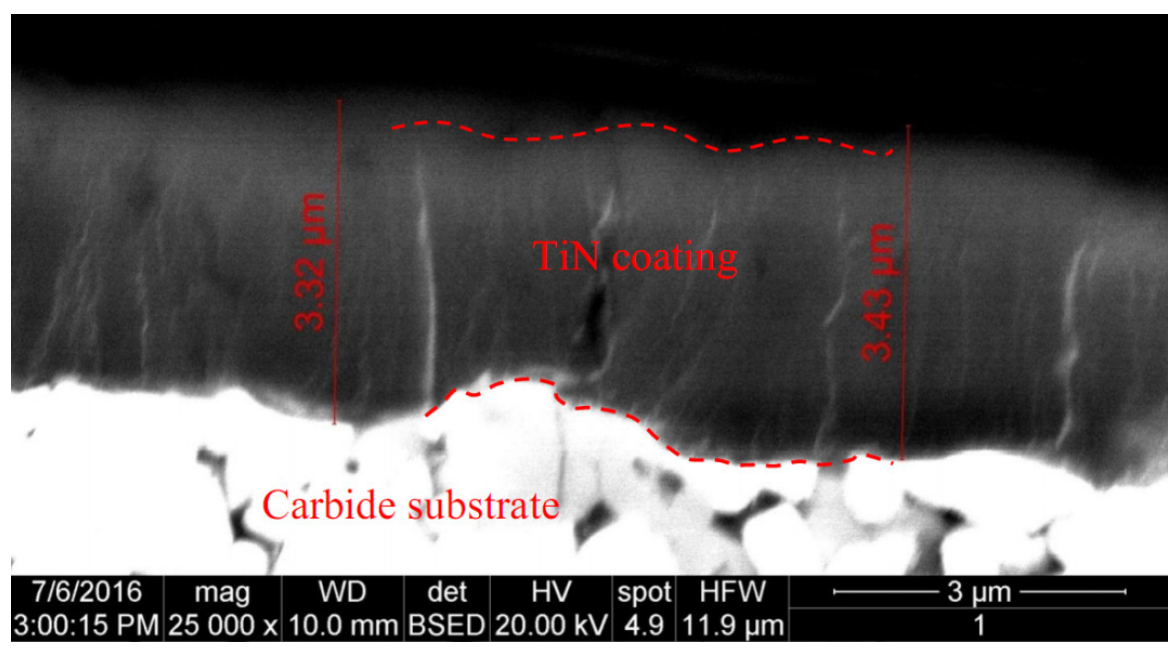

(a)

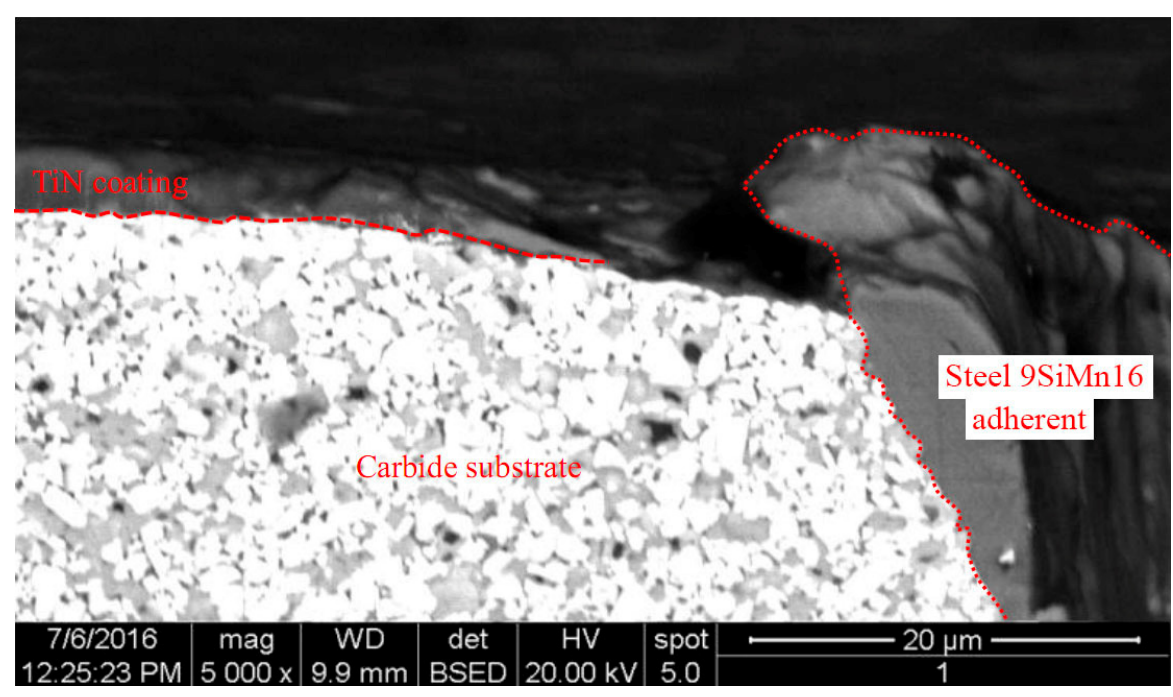

(b)

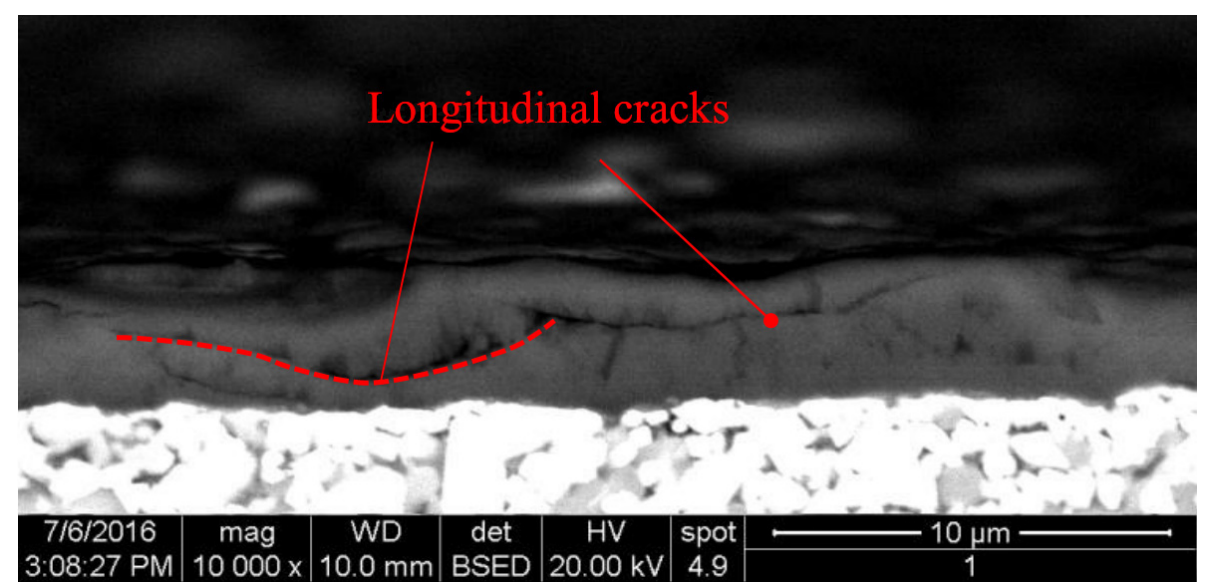

(c)

Fig. 7. Parameters and structure of composition "carbide substrate-TiN" (a); wear behavior of rake and flank faces of carbide tool with coating TiN (b) and failure behavior of single-layer coating TiN (c), after 10 min of cutting of workpiece of steel 9SiMn16 at $a_{\mathrm{p}}=0.5 \mathrm{~mm} ; f=0.2 \mathrm{~mm} \cdot \mathrm{rev}^{-1} ; v_{\mathrm{c}}=250 \mathrm{~m} \cdot \mathrm{min}^{-1}$. 


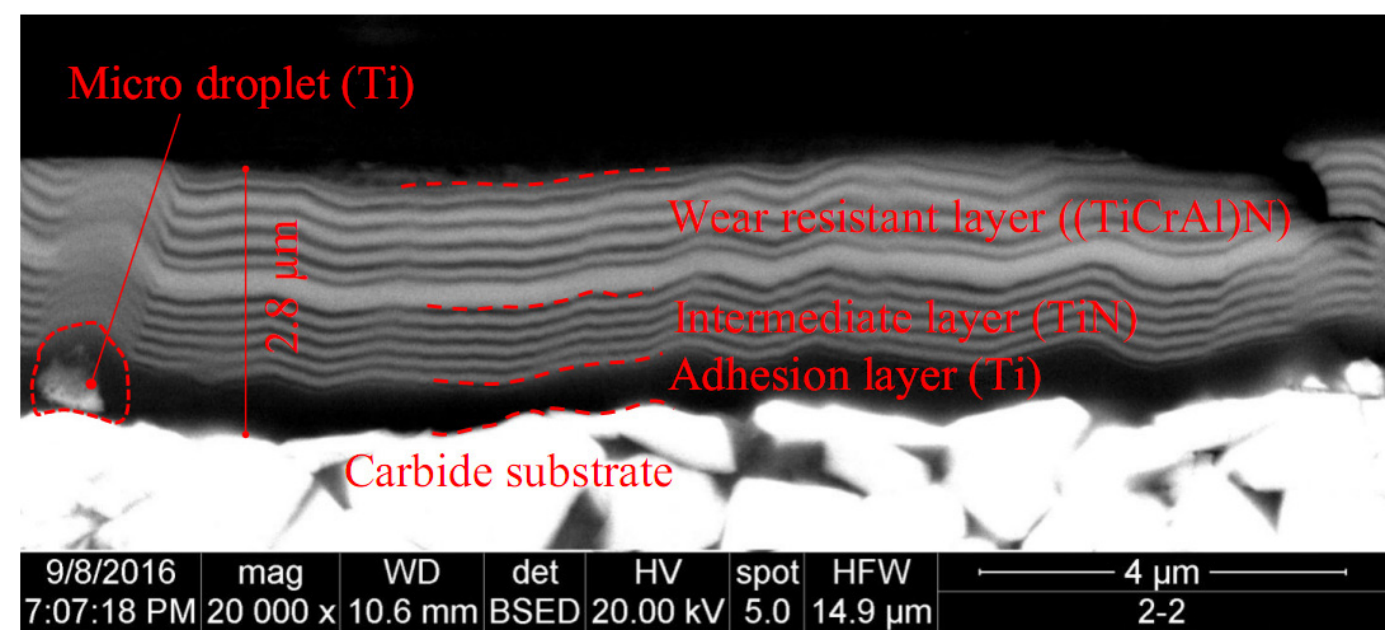

(a)

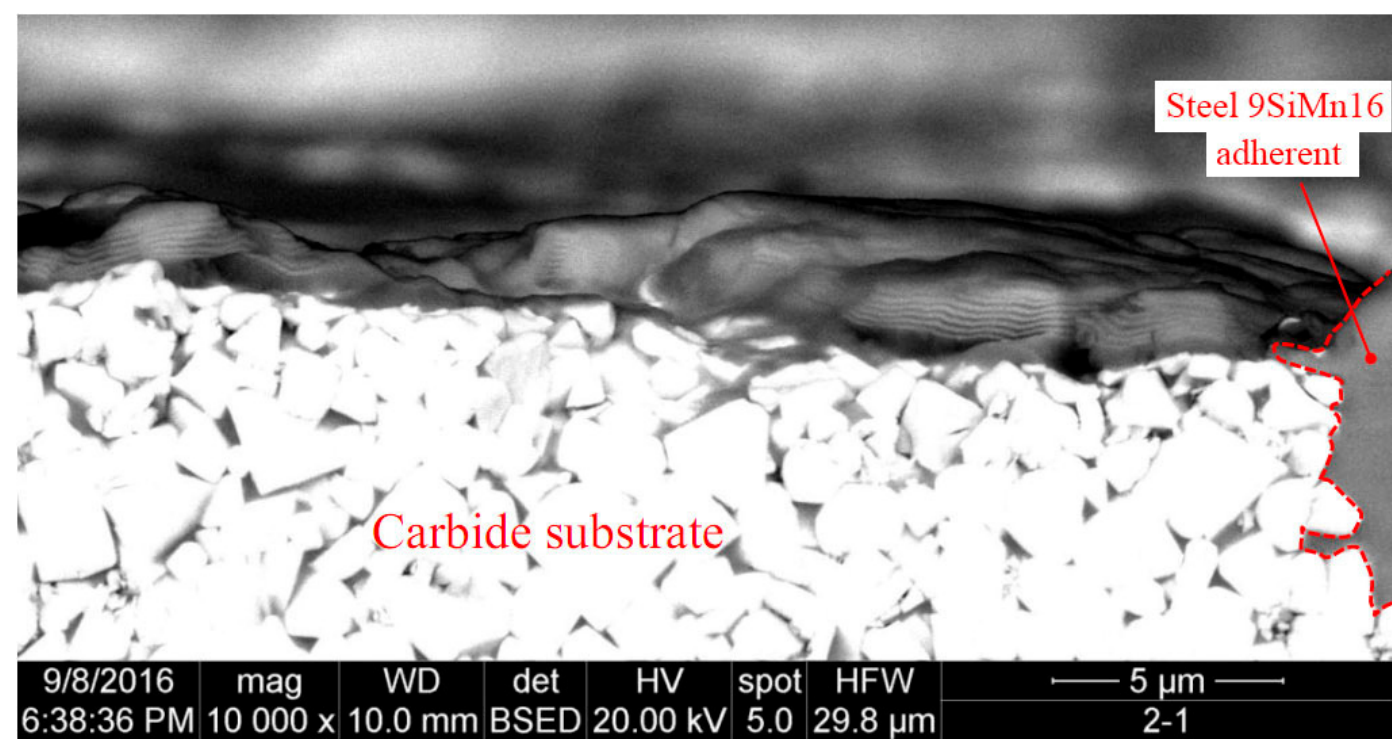

(b)

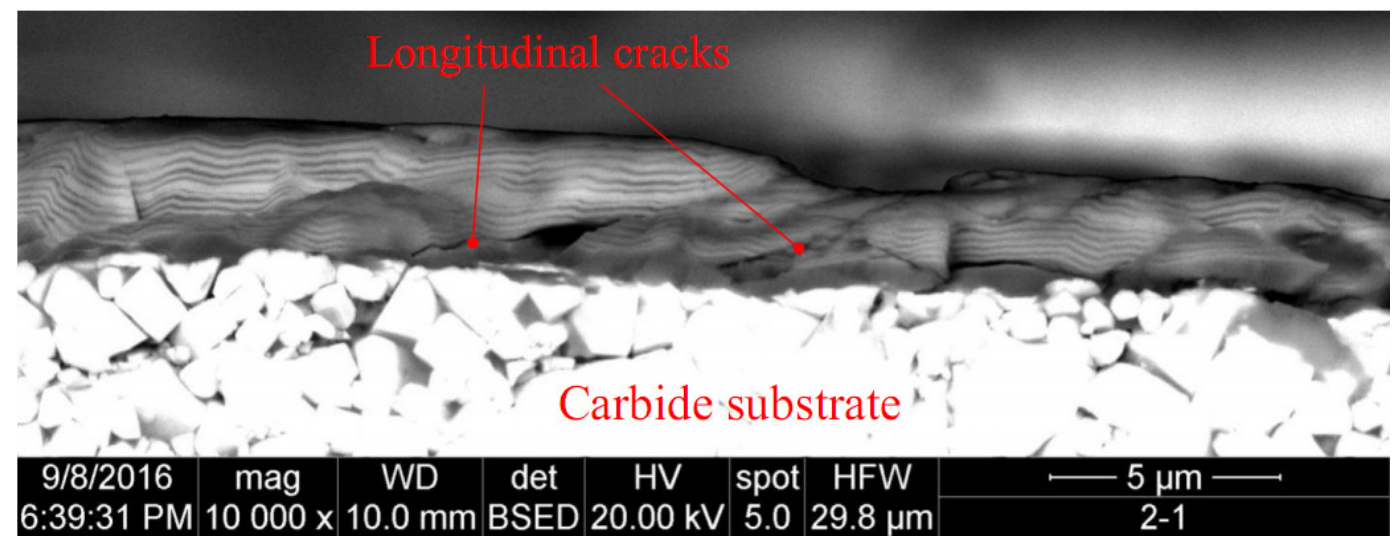

(c)

Fig. 8. Structure of NMCC Ti-TiN-(TiCrAl)N on rake face of a carbide tool deposited through the FCVAD technology (a) failure behavior of NMCC Ti-TiN-(TiCrAl) N on rake face of carbide tool after 15 min of cutting of steel 9SiMn16 at $a_{\mathrm{p}}=0.5 \mathrm{~mm}$; $f=0.2 \mathrm{~mm} \cdot \mathrm{rev}^{-1} ; v=350 \mathrm{~m} \cdot \mathrm{min}^{-1}(\mathrm{~b})$; and failure behavior of NMCC Ti-TiN-(TiCrAl)N on rake face of carbide tool after $20 \mathrm{~min}$ of cutting of steel 9SiMn16 at $a_{\mathrm{p}}=0.5 \mathrm{~mm} ; f=0.2 \mathrm{~mm} \cdot \mathrm{rev}^{-1} ; v=250 \mathrm{~m} \cdot \mathrm{min}^{-1}$ (c). 


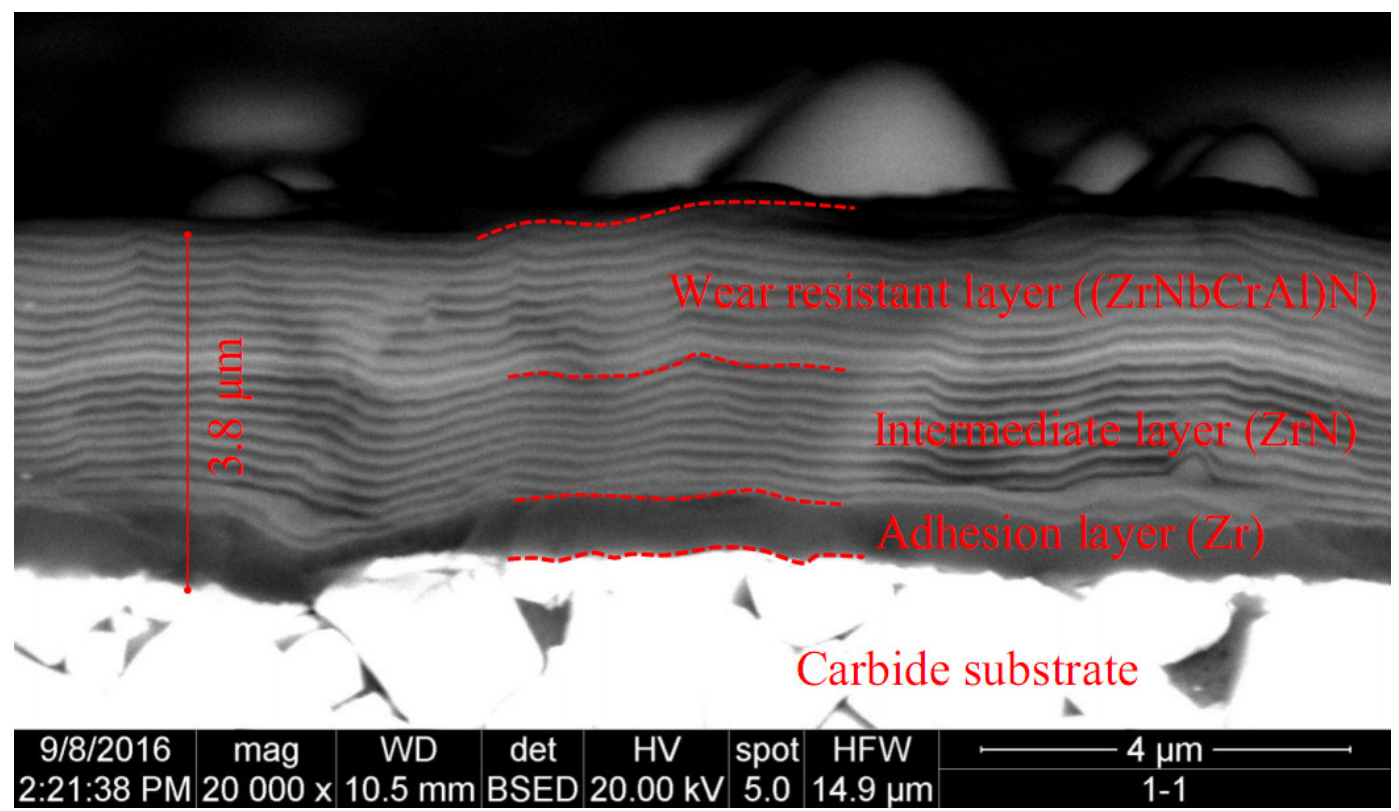

Fig. 9. Structure of NMCC $\mathrm{Zr}-\mathrm{ZrN}-(\mathrm{ZrNbCrAl}) \mathrm{N}$, obtained through the FCVAD technology, on rake face of a carbide tool (a) pattern of formation of build-up after failure of NMCC Zr-ZrN-(ZrNbCrAl)N directly in area of tool cutting edge (b) and failure behavior of NMCC Zr-ZrN-(ZrNbCrAl) N on rake face of the carbide tool (c) after 20 min of cutting of steel $9 \mathrm{SiMn} 16$ at $a_{\mathrm{p}}=0.5 \mathrm{~mm} ; f=0.2 \mathrm{~mm} \cdot \mathrm{rev}^{-1} ; v=250 \mathrm{~m} \cdot \mathrm{min}^{-1}$.

of scientific activity of MSTU "STANKIN" (No. 1059). The work is carried out on the equipment of the Center of collective use of MSTU "STANKIN".

\section{References}

[1] H. Tönshoff, T. Friemuth, P. Andrae, R. Amor, Highspeed or high-performance cutting - a comparison of new machining technologies. Production Engineering. Res. Academic Soc. Production Eng. VIII/1 (2001) 1-8

[2] A. Vereschaka, A. Vereschaka, D. Klauch, D. Lytkin, A. Batako, High-efficiency machining of hard-to-cut materials used in heavy power engineering through the use of carbide tools with nano-scale multiphase coatings, Procedia CIRP 46 (2016) 356-359

[3] F. Klocke, K. Gerschwiler, Producing Turbine components - modern cutting materials improve productivity, in: Uhlmann, E. (ed.), Proceedings of IX Internationales Produktionstechnisches Kolloquium (PTK 98), Berlin, Germany, 1998, pp. 203-209

[4] E.O. Ezugwu, Key improvements in the machining of difficult-to-cut aerospace superalloys, Int. J. Mach. Tool Manuf. 45 (2005) 1353-1367

[5] DIN 6584-1982, Terms of the cutting technique; forces, energy, work, power, 1982

[6] F. Kafkas, An experimental study on cutting forces in the threading and the side cut turning with coated and uncoated grades, J. Manuf. Sci. Eng. 132 (2010) 041012

[7] G. Byrne, D. Dornfeld, I. Inasaki, G. Ketteler, W. Konig, R. Teti, Tool condition monitoring (TCM) - the status of research and industrial application, CIRP Ann. Manuf. Technol. 44 (1995) 541-567
[8] A.A. Vereschaka, M.A. Volosova, A.D. Batako, A.S. Vereshchaka, B.Y. Mokritskii, Development of wearresistant coatings compounds for high-speed steel tool using a combined cathodic vacuum arc deposition, J. Nano Res. 84 (2016) 1471-1482

[9] A.A. Vereschaka, A.S. Vereschaka, J.I. Bublikov, A.Y. Aksenenko, N.N. Sitnikov, Study of properties of nanostructured multilayer composite coatings of Ti-TiN(TiCrAl)N and Zr-ZrN-(ZrNbCrAl)N, J. Nano Res. 40 (2016) 90-98

[10] A.S. Vereschaka, A.A. Vereschaka, D.V. Sladkov, A. Yu. Aksenenko, N.N. Sitnikov, Control of structure and properties of nanostructured multilayer composite coatings applied to cutting tools as a way to improve efficiency of technological cutting operation, J. Nano Res. 37 (2016) $51-57$

[11] A.A. Vereshchaka, A.S. Vereshchaka, O. Mgaloblishvili, M.N. Morgan, A.D. Batako, Nanoscale multilayered-composite coatings for the cutting tools, Int. J. Adv. Manuf. Technol. 72 (2014) 303-317

[12] G.S. Fox-Rabinovich, K. Yamamoto, S.C. Veldhuis, A.I. Kovalev, G.K. Dosbaeva. Tribological adaptability of TiAlCrN PVD coatings under high performance dry machining conditions, Surf. Coat. Technol. 200 (2005) 18041813

[13] T. Childs, K. Maekawa, T. Obikawa, Y. Yamane, Metal machining - theory and applications, John Wiley and Sons, NewYork, 2000

[14] A.O. Volkhonskii, A.A. Vereshchaka, I.V. Blinkov, A.S. Vereshchaka, A.D. Batako, Filtered cathodic vacuum arc deposition of nano-layered composite coatings for machining hard-to-cut materials, Int. J. Adv. Manuf. Technol. 84 (2016) 1647-1660 